\section{The high effect of chemomobi- lization with high-dose etopside + granulocyte-colony stimulating factor in autolo- gous hematopoietic peripheral blood stem cell transplantation: a single center experience}

\author{
Sebnem Izmir Güner, ${ }^{1}$ \\ Mustafa Teoman Yanmaz, ${ }^{2}$ \\ Ahmet Selvi, ${ }^{3}$ Cigdem Usul ${ }^{4}$ \\ Departments of ${ }^{1}$ Hematology, ${ }^{2}$ Medical \\ Oncology, ${ }^{3}$ Pulmonary Medicine, Istanbul \\ Kemerburgaz University, Medical Park \\ Bahcelievler Hospital, Istanbul; \\ ${ }^{4}$ Department of Medical Oncology, \\ Istanbul Research and Education \\ Hospital, Istanbul, Turkey
}

\section{Abstract}

Autologous hematopoietic stem cell transplantation (auto-HSCT) provides hematopoietic support after high-dose chemotherapy and is the standard of care for patients with multiple myeloma (MM), chemo sensitive relapsed high or intermediate grade non-Hodgkin's lymphoma (NHL) and Hodgkin's lymphoma (HL). However, yields of hematopoietic stem cells vary greatly between patients, and the optimal strategy to mobilize hematopoietic stem cells into peripheral blood for collection has not been defined yet. We investigated the efficacy and safety of chemo mobilization with an intermediate dose etoposide (VP-16; 200 $\mathrm{mg} / \mathrm{m}^{2}$ on days $1-3$ ) and granulocyte-colony stimulating factor (G-CSF) $(5 \mu \mathrm{g} / \mathrm{kg}$ twice daily from day 4 through the final day of collection). We reviewed our institutional experience with 91 patients (71 MM, 12 HL, 8 NHL) mobilized with this regimen. VP-16 + G-CSF resulted in successful mobilization in $95.55 \%$ of the patients (on one patient stem cell collection with plerixafor was applied), including 76 patients $(83.52 \%)$ whose stem cells were collected successfully in a single day. Collection was managed between min. D8 and max. D17. Patient age, gender, exposure to previous irradiation and chemotherapy, previous mobilization attempts, and disease characteristics were not considered during selection. Adverse effects of the regimen included supportive transfusions and fevers requiring hospitalization or intravenous antibiotics. VP-16 and GCSF appears to be a safe and effective mobilization regimen for patients with multiple myeloma, non-Hodgkin's lymphoma and Hodgkin's lymphoma undergoing autologous stem cell transplantation, producing excellent stem cell yield with the majority of patients requiring 1 day of apheresis.

\section{Introduction}

Autologous hematopoietic SCT (auto-HSCT) is the standard of care for patients with multiple myeloma (MM) or chemosensitive relapsed higher and intermediate grade non-Hodgkin's lymphoma (NHL) and Hodgkin's lymphoma (HL). Also it provides essential hematopoietic support after the administration of high-dose therapy (HDT). ${ }^{1,2}$

Although MM is an incurable malignancy, auto-HSCT used in conjunction with HDT has shown to prolong survival. ${ }^{3-5}$ The rates of complete response to conventional therapy without auto-HSCT in patients with MM are between 5$15 \%{ }^{4-6}$ Auto-HSCT in combination with HDT can increase the rates of complete response to $20-44 \%$ and is associated with a very low incidence of treatment treated mortality 1,6

Auto-HSCT combined with HDT administration after relapse, has shown to prolong the duration of remission in patients with diffuse large B-cell lymphoma and provides these patients with approximately a $45 \%$ probability of long-term disease free survival. ${ }^{2}$ Auto-HSCT is also used in conjunction with high-dose myeloablative therapy as a salvage treatment for follicular lymphoma. Although controversial, recent data suggest that more than 10year disease free survival is possible after salvage auto-HSCT for patients with follicular lymphoma and Hodgkin's lymphoma. ${ }^{7}$ In addition, auto-HSCT may improve the prognosis in patients with mantle cell lymphoma, specifically when it is used as part of first-line treatment.

The success of auto-HSCT is influenced by a number of factors. The most important one is the dose of reinfused stem cells. Higher stem cell doses are associated with faster platelet (PLT) engraftment (generally defined as PLT count $>20 \times 10^{9} / \mathrm{L}$ ), faster neutrophil (ANC) engraftment (generally defined as ANC $\left.>0.5 \times 10^{9} / \mathrm{L}\right)^{7-12}$ and reduction in the need for supportive measures such as transfusions of packed red blood cells (RBCs) and PLT and administration of prophylactic antibiotics. ${ }^{7,13}$

In some studies, higher stem cell doses have been associated with higher rates of survival for patients. ${ }^{14,15}$ Other factors that affect collection efficiency and the success of autoHSCT include patient age, gender, exposure to previous irradiation and chemotherapy, previous mobilization attempts, and disease characteristics such as the involvement of bone marrow (BM). ${ }^{15,16}$ Unsuccessful initial stem cell mobilization leads to costly additional mobilization attempts and even may prohibit autoHSCT.6,14-16 Current regimens to mobilize
Correspondence: Sebnem Izmir Güner, Department of Hematology, Istanbul Kemerburgaz University, Medicalpark Bahçelievler Hospital, Istanbul, Turkey.

Tel.: +90.212.483.1206

E-mail: sebnemizmirguner@gmail.com

Key words: Autologous hematopoietic peripheral blood stem cell transplantation; chemomobilizatio; etopside.

Contributions: the authors contributed equally.

Conflict of interest: the authors declare no potential conflict of interest.

Received for publication: 20 November 2015. Revision received: 13 March 2016.

Accepted for publication: 13 March 2016.

This work is licensed under a Creative Commons Attribution-NonCommercial 4.0 International License (CC BY-NC 4.0).

(C) Copyright SS.I. Güner et al., 2016

Licensee PAGEPress, Italy

Hematology Reports 2016; 8:6319

doi:10.4081/hr 2016.6319

PBSC for auto-HSCT have differing stem cell yields, safety considerations, resource utilization, and levels of contamination of the apheresis product with tumor cells. ${ }^{2,16}$ The two most common mobilization strategies are using cytokines alone or cytokines after chemotherapy.

Mobilization using Food and Drugs Administration approved cytokines alone is generally well tolerated; however, yields are often suboptimal and collection of sufficient numbers of stem cells to support transplantation can be difficult, particularly in patients who have previously been treated with multiple rounds of intensive chemotherapy. ${ }^{14}$ The efficiency of granulocyte-colony stimulating factor (G-CSF) alone in certain patient groups is quite good, although there have been several different patient populations identified as difficult to mobilize. Failure rates of G-CSF alone have been variably reported between $1 \%$ and $40 \% .{ }^{17}$

Recently, in large phase 3 studies, only $34 \%$ of patients mobilized with only G-CSF are able to collect $6 \times 10^{6} \mathrm{CD} 34^{+}$cells $/ \mathrm{kg}$ in 2 days of apheresis. ${ }^{18}$

In contrast, mobilization with chemotherapy in addition to cytokine has been previously demonstrated to increase stem cell yields at the time of collection. ${ }^{16}$ Most of this data has been reported with the use of cyclophosphamide (Cy) in addition to G-CSF, in which stem cell yields and failure rates have been improved in comparison to G-CSF alone.

The addition of a myelosuppressive chemotherapeutic agent to a cytokine mobi- 
lization regimen improves collections by a factor of 2.5 and can reduce the number of apheresis sessions needed for cell collection. ${ }^{18,19}$

Potential disadvantages of adding chemotherapy to mobilization include increased complications such as cytopenias requiring transfusion support, febrile neutropenia requiring hospitalization, and intravenous antibiotics. Further disadvantages are inability to schedule patients for apheresis due to difficulty in predicting peak PB CD $34^{+}$cell recovery, unpredictability regarding the optimal day for stem cell collection and delayed engraftment. $3,9,10,15$

Conversely, other studies have demonstrated comparable ANC and PLT engraftment kinetics for patients mobilized with either chemotherapy in combination with cytokines or cytokines alone. ${ }^{3,8-10,14}$ Although growth factor mobilization is associated with lower cell yields when compared to chemomobilization, ${ }^{3,8-10,16}$ it is also associated with lower toxicity and more predictable mobilization, thereby permitting easy apheresis scheduling.

There is available data that support the ability of high-dose etoposide (VP-16) to effectively mobilize progenitor cells. ${ }^{9}$ There is also one data about the routine addition of VP-16 to GCSF in the mobilization of patients with MM. ${ }^{10}$

This study was aimed to use an intermediate dose of etoposide $\left(200 \mathrm{mg} / \mathrm{m}^{2}\right.$ per day for 3 days) to preserve progenitor cell mobilization and antitumor properties while limiting other potential toxicities including myelodysplasia, mucositis, hepatic dysfunction, or prolonged cytopenias associated with higher doses of this or other agents. With this institutional experience we are reporting the safety and efficacy of this regimen.

\section{Materials and Methods}

\section{Patients and treatment}

This study was conducted on 91 patients between the ages of 20 and 67 years who received mobilization with VP-16 and G-CSF prior to ASCT for MM, NHL and HL at our institution between the years 2010 and 2014. The mobilization regimen consisted of placement of a central apheresis catheter (Hickman hemodialysis/apheresis long term central venous catheter) followed by administration of intravenous VP-16 (200 mg/m²) once daily on D1-3. Each VP-16 infusion was diluted to a concentration of $0.5 \mathrm{mg} / \mathrm{mL}$ and infused over 4 hours. G-CSF was administered at a dose of 5 $\mu \mathrm{g} / \mathrm{kg}$ twice daily starting on D 4 and continuing through the last day of stem cell collection. Antimicrobial prophylaxis was not given.
Complete blood counts were determined daily. Monitoring of peripheral blood CD34+ cell counts, was started when the WBC count in the blood exceeds 1.0 to $5.0 \times 10^{9} / \mathrm{L}$. Apheresis was performed daily using continuous flow blood cell separators, Fenwal CS3000 Plus (Fenwal, Deerfield, IL, USA). Peripheral blood CD $34^{+}$cell counts were checked routinely, except for the patients who to have normal or high total white blood cell counts. Apheresis was initiated when the peripheral blood CD34 ${ }^{+}$ cell count was $>20 / \mu \mathrm{L},{ }^{11}$ and all patients had stem cells collected between days 8 and 17 (median day 11.31, after D1 of chemotherapy). $\mathrm{CD} 34^{+}$determination was conducted in daily leukapheresis samples before cryopreservation with $10 \%$ dimethylsulfoxide by controlledrate freezing. Cells were stored at $-196^{\circ} \mathrm{C}$ until thawing for transplantation.

Target volumes were calculated based on an algorithm that includes the patient's weight in kilograms, the peripheral precollection CD $34^{+}$ count, and the requested cell dose (usually a minimum of $2.39 \times 10^{6} \mathrm{CD} 34^{+}$cells $/ \mathrm{kg}$ and a maximum of $84.93 \times 10^{6} \mathrm{CD} 34^{+}$cells $/ \mathrm{kg}$ ) (median $33.73 \times 10^{6} \mathrm{CD}^{2} 4^{+}$cell/kg). The main goal of the collection was to obtain more than $2,0 \times 10^{6} / \mathrm{kg}$ patient body weight of $\mathrm{CD} 34^{+}$cells. $\mathrm{CD} 4^{+}$cells were determined according to the International Society of Hematotherapy and Graft Engineering Guidelines as previously described. All collections were done using the Fresenius kabi Com.tec.continous flow separator cell equipment (Fresenius kabi, Bad Homburg, Germany).

Platelet transfusions were administered routinely for platelet counts $<10.000 \times 10^{9} / \mathrm{L}$, with higher thresholds used for patients at a higher risk for clinically significant bleeding. ASCT was performed using melphalan (200 $\mathrm{mg} / \mathrm{m}^{2}$, reduced to $140 \mathrm{mg} / \mathrm{m}^{2}$ for patients with comorbid illness) for MM patients or BEAM chemotherapy protocol for $\mathrm{HL}$ and NHL patients followed by stem cell infusion.

\section{Results}

Between years 2010 and 2014, a total of 91 patients with MM, NHL and HL underwent stem cell mobilization. Collection with VP-16 and G-CSF were followed by ASCT in 91 patients (one patient was collected with plerixafor).

Among these, 60 (65.94\%) were male and 31 (34.07\%) were female. The median age at the time of transplant was 52.61 years, with a range of 20 to 67 years.

Patients had received several lines of prior treatment for myeloma or lymphoma. 48 patients $(52.75 \%)$ received 1 prior treatment regimen, 37 patients (40.66\%) received 2 regimens, 3 patients $(3.3 \%)$ received 3 regimens, and 3 patients $(3.3 \%)$ received 4 prior regimens.

The NHL and HL diagnosed patients were all in remission; MM diagnosed patients were 30 $(42.25 \%)$ in remission and 41 (57.75\%) in very good response position (VGPR-Very Good Partial Remission) before collecting their stem cell. Median bone marrow (BM) cellularity prior to mobilization for patients with this information available on chart review was $55 \%$ (range: $60-95 \%$ ), with a median $5 \%$ plasma cell involvement (range: 1-10\%) in MM patients; the other patients (HL and NHL patients) haven't any bone marrow disease involvement (Table 1).

On 76 patients $(83.52 \%)$ stem cells were successfully collected after 1 day of apheresis, 13 patients (14.29\%) required 2 days of collection, 2 patients (2.2\%) required 3 days of collection. Patients collected on min. day 8 , with the max. Day 17 (median day 11,31).

The median peak peripheral blood CD34+ cell count during the collection period was 193.7/ $\mathrm{LL}$ and the median collected CD $34^{+}$cell number was $33.73 \times 10^{6}$ cells $/ \mathrm{kg}$ (range: $\left.2.39 \times 10^{6}-84.93 \times 10^{6}\right)$. Viabilite median range was $15.14 \times 10^{6}$ cells $/ \mathrm{kg}$ (range: $2.01 \times 10^{6}$. $83.76 \times 10^{6}$ ). The patient with poor mobilized has a CD $34^{+}$cell of $2.39 \times 10^{6}$ cells $/ \mathrm{kg}$.

The median time to neutrophil engraftment was 11.3 days (min. 6 days, max. 23 days), and the median time to a platelet count $>20,000$ for more than 7 days without transfusion were 13.92 days (min. 7 days, max. 30 days). There was one patient who was defined as poor engrafters, engrafting beyond one standard deviation, which was more than 23 days for neutrophils and 30 days for platelets (Table 2).

Antibacterial therapy was given about median 21 days after a febrile neutropenic attack.

The patient's hospitalization time was median 32.48 days (min. 19 days, max. 63 days).

Because of the high efficacy of this mobilization regimen and thus the very small number of poor mobilizers, none of the following variables were associated with poor mobilization in this patient population: age, receipt of prior radiation therapy, duration of prior chemotherapy, BM cellularity and disease involvement at the time of mobilization, peripheral white blood cell count and platelet count at the time of mobilization.

\section{Survival and relapse information}

Out of the total of 91 patients that had been followed for survival information, 8 have died and 83 were still alive at the time of analysis. The median follow-up time for survivors was 48 months. Ten patients have either relapsed (2 MM patients received lenalidomide treat- 
ment and 8 had a second autologous stem cell transplantation).

\section{Discussion}

It is widely accepted that the standard of care for treating certain patients with relapse/refractory lymphoma and MM includes high-dose chemotherapy in conjunction with autologous HSCT. ${ }^{11,12}$

There remains little consensus about the optimal method for mobilizing patients prior to autologous HSCT for MM, NHL and HL. Although increasingly, there is recognition that some populations of patients are difficult to mobilize with a standard regimen of G-CSF alone. $^{20}$

The efficacy of G-CSF alone for mobilization of PBSCs for auto-HSCT was established in a phase 3 study in which 58 patients with NHL or HL received either PBSCs mobilized with GCSF $10 \mu \mathrm{g} / \mathrm{kg}$ s.c. daily for 6 consecutive days $(n=27)$ or BM $(n=31)$ for hematopoietic reconstitution after HDT. A median value of $2.8 \times 10^{6} \mathrm{CD} 34^{+}$cells $/ \mathrm{kg}$ was collected after GCSF mobilization. Furthermore, when com- pared with BMT, reinfusion of G-CSF-mobilized PBSCs was found to reduce the number of PLT infusions needed ( 6 vs $10, \mathrm{P}=0.001)$ and the time to PLT and ANC engraftment (16 days vs 23 days, $\mathrm{P}=0.02 ; 11$ days vs 14 days, $\mathrm{P}=0.005$, respectively). ${ }^{21}$

Nademanee et al. harvested stem cells in 95 patients with lymphoma after the s.c. or i.v. administration of regimens of G-CSF $10 \mu \mathrm{g} / \mathrm{kg}$ daily for a median of 12 days (range: 4-23; $\mathrm{n}=39$ ), G-CSF $5 \mu \mathrm{g} / \mathrm{kg}$ daily for a median of 12 days (range: $8-27 ; n=26$ ) or no mobilizing therapy $(n=30)$. The authors reported median $\mathrm{CD}^{+} 4^{+}$cell yields of $6.2 \times 10^{6}$ cells $/ \mathrm{kg}, 3.4 \times 10^{6}$ cells $/ \mathrm{kg}$ and $1.2 \times 10^{6} \mathrm{cells} / \mathrm{kg}$ in the respective treatment groups. ${ }^{22}$ Twenty-eight mobilized stem cells in 22 patients with NHL or HL by using G-CSF $10 \mu \mathrm{g} / \mathrm{kg}$ s.c. daily for 4 days before the start of apheresis and reported a median $\mathrm{CD}^{2} 4^{+}$cell collection of $2.5 \times 10^{6} / \mathrm{kg}$; approximately $50 \%$ of these patients required only one apheresis session, whereas $4 \%$ of patients required three sessions.

In many patients with MM or NHL, mobilization with G-CSF as a single agent results in suboptimal $\mathrm{CD} 34^{+}$cell yields. These studies show that CD34+ cell yields are generally lower when a cytokine-only mobilization regimen is

Table 1. Patients' characteristics.

\begin{tabular}{lc} 
Variable & Number \\
Total & 91 \\
Median age, range & $52.61(20-67)$ \\
\hline Male sex, \% & $60(65.94)$ \\
Female sex, \% & $31(34.06)$ \\
\hline Number of prior treatment regimens, \% & \\
$\quad 1$ & $48(52.75)$ \\
2 & $37(40.66)$ \\
3 & $3(3.3)$ \\
4 & $3(3.3)$ \\
Prior radiation therapy, \% & $24(26.37)$ \\
\hline Marrow cellularity percentage prior to mobilization (range) & $55(60-95)$ \\
Marrow disease involvement at mobilization (range), \% & $5(0-10)$ \\
\hline
\end{tabular}

Table 2. Mobilization efficacy.

\begin{tabular}{lc} 
Criteria & Number \\
Successful collection after 1 mobilization, \% & $76(83.52)$ \\
Patients collecting $>10 \times 106 \mathrm{CD} 34^{+}$cells/kg, \% & $48(43.68)$ \\
\hline Patients collecting $>5-10 \times 10^{6} \mathrm{CD} 34^{+}$cells/kg, \% & $28(30.76)$ \\
Patients collecting $<4 \times 10^{6} \mathrm{CD} 34^{+}$cells/kg, \% & $15(25.56)$ \\
\hline Days of collection required, \% & \\
1 & $76(83.52)$ \\
2 & $13(14.29)$ \\
3 & $2(2.2)$ \\
Median CD34+ cells/kg $10^{6}$ collected (range) & $33.73(2.39-84.93)$ \\
\hline Median days to neutrophil engraftment & $11.30(6-23)$ \\
Median days to platelet engraftment & $13.92(7-30)$ \\
\hline
\end{tabular}

used than when cytokine mobilization is used with chemotherapy. In addition, mobilization failures (defined as $\mathrm{CD} 34^{+}$cell yields of $>2.0 \times 10^{6} / \mathrm{kg}$ ) were highly variable throughout these studies, ranging from 0 to $23 \%$.

In a study of 52 patients with $\mathrm{NHL},{ }^{23}$ it was reported that mobilization with G-CSF alone (16 $\mu \mathrm{g} / \mathrm{kg}$ s.c. daily for 4-6 days) failed to yield adequate numbers of $\mathrm{CD} 34^{+}$cells in $35 \%$ of patients.

Efforts to determine factors associated with poor mobilization have focused largely on age, amount, and type of prior chemotherapy or biologic therapy, and amount of prior radiation therapy received. . $^{10,24}$

For this reason, the International Myeloma Working Group has recently released suggested guidelines for stem cell collection in patients who have received prior therapy with novel agents. These include the use of early stem cell mobilization after 3 to 4 cycles of initial therapy or the addition of other mobilization agents in higher risk groups, such as patients who have received more than 4 cycles of therapy or who are older than 65 years of age. ${ }^{10}$ Several prior studies have suggested that adding chemotherapy, most often Cytarabine (CY), to mobilization can improve cell yields when compared with G-CSF alone. One recent publication suggests that the addition of cyclophosphamide to G-CSF can overcome the effects of prior lenalidomide exposure. An alternative strategy that has been proposed to increase cell yields has been the addition of plerixafor (AMD3100) to G-CSF, an approach that was recently demonstrated to improve the chance of successful mobilization in comparison with G-CSF alone. ${ }^{10}$

The safety profile of intermediate dose VP16 and G-CSF appears acceptable, as more than $80 \%$ of the population don't require treatment for fever or supportive transfusions during the mobilization period. ${ }^{10}$

In a study, $152 \mathrm{MM}$ patients were mobilized with intermediate dose etoposide (VP-16; 375 $\mathrm{mg} / \mathrm{m}^{2}$ on days 1 and 2) and granulocyte-colony stimulating factor (G-CSF) $(5 \mu \mathrm{g} / \mathrm{kg}$ twice daily from day 3 through the final day of collection). The addition of VP-16 to G-CSF resulted in successful mobilization in $100 \%$ of patients, including 143 of them (94\%) who collected successfully in a single day. A total of $99 \%$ of patients, including those with prior XRT and/or prior lenalidomide or thalidomide therapy, collected at least $5 \times 10^{6} \mathrm{CD} 34^{+}$cells $/ \mathrm{kg}$ in 1 or 2 days of apheresis, and the median total number of $\mathrm{CD} 34^{+}$cells collected in the entire population was $12 \times 10^{6} \mathrm{cells} / \mathrm{kg}$. Collection was predictable, with $61 \%$ of patients collecting on day 11 , and the rest between days 7 and $13 .{ }^{10}$ In our study the median collected CD $34^{+}$cell number was $33.73 \times 10^{6}$ cells $/ \mathrm{kg}$.

One potential advantage of the chemotherapy plus G-CSF approach is improved tumor 
control, as others have observed an antitumor effect in MM patients following the outpatient administration of VP-16 with G-CSF. ${ }^{9}$

The timing of collection with VP-16 and GCSF also appeared to be very predictable, with most patients collecting on 1 day. In our study 76 patients $(83,52 \%)$ of 91 patients stem cells were successfully collected after 1 mobilization. Finally, there was no obvious adverse consequence of exposure to VP-16 on ANC or PLT engrafment after subsequent autologous stem cell transplantation.

Our study group encompassed patients with various hematological malignancies. Most of the patients had received $>2$ lines treatment. The number of $\mathrm{CD}^{+} 4^{+}$cell yield in acute leukemia patients was relatively lower compared to patients with other disorders, which could not be statistically, documented due to small numbers of the patients study group. An Italian retrospective study reported that acute myeloid leukemia patients had the highest incidence of poor mobilization among patients with hematologic malignancies. ${ }^{11}$ It is published that $10-30 \%$ of NHL patients were reported to be hard-to-mobilize or experienced a mobilization failure with standard protocols. ${ }^{12}$ On the other hand with a combination of CY and G-CSF, more than 95\% of MM patients eligible for autologous stem cell transplantation could be successfully mobilized. ${ }^{7}$

Our mobilization success was highly striking. On 76 patients (83.52\%) stem cells were successfully collected after 1 mobilization. The median collected $\mathrm{CD} 34^{+}$cell number was $33.73 \times 10^{6}$ cells $/ \mathrm{kg}$. The high collected CD $34^{+}$ cell number pickup the engratment of neutrophil and PLT.

The side effects of mobilization chemotherapy were acceptable. Adverse effects of the regimen included supportive transfusions required in 59 patients $(64.83 \%)$, and 30 patients (32.96\%) with fever requiring hospitalization and intravenous antibiotics. Grade III or IV hematopoietic toxicity of chemotherapy had no significant effect on the mobilization efficacy. Supportive care and the incidence of febrile neutropenia were not significantly different from literature reported in $\mathrm{CY}$ plus G-CSF used mobilization regimen. ${ }^{10}$

\section{Conclusions}

In conclusion, we demonstrated that highdose etoposide plus G-CSF mobilization represents an effective and well-tolerated chemomobilization for patients with various hematological malignancies and eligible for autologous transplantation.

Collectively, all regimens in current usage fail to mobilize adequate numbers of $\mathrm{CD} 34^{+}$ cells in $5-30 \%$ of patients.
High failure rates can adversely affect patient outcomes, because these patients cannot proceed to transplantation without a repetition of mobilization and apheresis, which is associated with increased morbidity and resource utilization. Because of these reasons, advances in mobilization strategies are needed to improve patient outcomes. Novel agents used in conjunction with existing therapies have the potential to amplify $\mathrm{CD} 34^{+}$cell yields without introducing additional toxicity, thereby improving the process of PBSC mobilization in patients undergoing auto-HSCT for MM or NHL and HL.

The future of mobilization will use promising new agents in the context of a patient-tailored strategy that depends on individual disease characteristics and the nature of previous treatment.

\section{References}

1. Pettengell R, Morgenstern GR, Woll PJ, et al. Peripheral blood progenitor cell transplantation in lymphoma and leukemia using a single apheresis. Blood 1993;82:3770-7.

2. Weaver CH, Hazelton B, Birch R, et al. An analysis of engraftment kinetics as a function of the CD34 content of peripheral blood progenitor cell collections in 692 patients after the administration of myeloablative chemotherapy. Blood 1995;86:3961-9.

3. Tricot G, Jagannath S, Vesole D, et al. Peripheral blood stem cell transplants for multiple myeloma: identification of favorable variables for rapid engraftment in 225 patients. Blood 1995;85:588-96.

4. Child JA, Morgan GJ, Davies FE, et al. High-dose chemotherapy with hematopoietic stem cell rescue for multiple myeloma. N Engl J Med 2003;348:1875-83.

5. Hari P, Pasquini MC, Vesole DH. Cure of multiple myeloma - more hype, less reality. Bone Marrow Transplant 2006;37:1-18.

6. Attal M, Harousseau JL, Stoppa AM, et al. A prospective, randomized trial of autologous bone marrow transplantation and chemotherapy in multiple myeloma. Intergroupe Francais du Myelome. N Engl J Med 1996;335:91-7.

7. Siena S, Schiavo R, Pedrazzoli P, CarloStella C. Therapeutic relevance of CD34 cell dose in blood cell transplantation for cancer therapy. J Clin Oncol 2000;18:136077.

8. Pavone V, Gaudio F, Console G, et al. Poor mobilization is an independent prognostic factor in patients with malignant lymphomas treated by peripheral blood stem cell transplantation. Bone Marrow
Transplant 2006;37:719-24.

9. Bolwell BJ, Pohlman B, Rybicki L, et al. Patients mobilizing large numbers of CD34+cells (super mobilizers) have improved survival in autologousstem cell transplantation for lymphoid malignancies. Bone Marrow Transplant 2007;40: 437-41.

10. Wood W, Whitley J, Moore D, et al. Chemomobilization with etoposide is highly effective in patients with multiple myeloma and overcomes the effects of age and prior therapy. Biol Blood Marrow Transplant 2011;17:141-6.

11. Johnston A, Coiffier B. HSCT for highgrade non-Hodgkin's lymphoma in adults. In: Apperley J, Carreras E, Gluckman E, et al, eds. The EBMT handbook: haematopoietic stem cell transplantation. Paris: European School of Haematology; 2008. pp 435-440.

12. Zelenetz AD, Abramson JS, Advani RH, et al. National comprehensive cancer network: clinical practice guidelines in oncology: non-Hodgkin's lymphoma. J Natl Compr Canc Netw 2010;8:288-334.

13. Sola C, Maroto P, Salazar R, et al. Bone marrow transplantation: prognostic factors of peripheral blood stem cell mobilization with cyclophosphamide and filgrastim ( $r$ metHuG-CSF): the CD34+ cell dose positively affects the time to hematopoietic recovery and supportive requirements after high-dose chemotherapy. Hematology 1999;4:195-209.

14. Philip T, Guglielmi C, Hagenbeek A, et al. Autologous bone marrow transplantation compared with salvage chemotherapy in relapses of chemotherapy-sensitive nonHodgkin's lymphoma. N Engl J Med 1995;333:1540-5.

15. Toor AA, Ayers J, Strupeck J, et al. Favourable results with a single autologous stem cell transplant following conditioning with busulphan and cyclophosphamide in patients with multiple myeloma. Br J Haematol 2004;124:769-76.

16. Alegre A, Tomas JF, Martinez-Chamorro C, et al. Comparison of peripheral blood progenitor cell mobilization in patients with multiple myeloma: high-dose cyclophosphamide plus GM-CSF vs G-CSF alone. Bone Marrow Transplant 1997;20:211-7.

17. Ford CD, Greenwood J, Anderson J, et al. CD34+ cell adhesion molecule profiles differ between patients mobilized with granulocyte-colony-stimulating factor alone and chemotherapy followed by granulocyte-colonystimulating factor. Transfusion 2006;46:193-8.

18. Hiwase DK, Bollard G, Hiwase S, et al. Intermediate-dose CY and G-CSF more efficiently mobilize adequate numbers of PBSC for tandem autologous PBSC trans- 
plantation compared with low-dose CY in patients with multiple myeloma. Cytotherapy 2007;9:539-47.

19. Dingli D, Nowakowski GS, Dispenzieri A, et al. Cyclophosphamide mobilization does not improve outcome in patients receiving stem cell transplantation for multiple myeloma. Clin Lymphoma Myeloma 2006;6:384-8.

20. Bensinger W, Persio JF, and McCarty JM. Improving stem cell mobilization strategies: future directions. Bone Marrow Transplant 2009;43:181-95.
21. Moskowitz CH, Glassman JR, Wuest D, et al. Factors affecting mobilization of peripheral blood progenitor cells in patients with lymphoma. Clin Cancer Res 1998;4:311-16.

22. Nademanee A, Sniecinski I, Schmidt GM, et al. High-dose therapy followed by autologous peripheral-blood stem-cell transplantation for patients with Hodgkin's disease and non-Hodgkin's lymphoma using unprimed and granulocyte colony-stimulating factor-mobilized peripheral-blood stem cells. J Clin Oncol 1994;12:2176-86.
23. Micallef IN, Apostolidis J, Rohatiner AZ, et al. Factors that predict unsuccessful mobilisation of peripheral blood progenitor cells following G-CSF alone in patients with non-Hodgkin's lymphoma. Hematol J 2000;1:367-73.

24. Rohatiner AZ, Nadler L, Davies AJ, et al. Myeloablative therapy with autologous bone marrow transplantation for follicular lymphoma at the time of second or subsequent remission: long-term follow-up. J Clin Oncol 2007;25:2554-9. 